\title{
ANALISIS PERANCANGAN POMPA GUNA PEMENUHAN KEBUTUHAN AIR BERSIH PDAM KOTA AMUNTAI
}

\author{
${ }^{(1)}$ Wahyudi, ${ }^{(2)}$ Sobar Ihsan, ${ }^{(3)}$ Abdurahim Sidiq \\ ${ }^{(1)(2)}$ Prodi Teknik Mesin Fakultas Teknik, Universitas Islam Kalimantan MAB \\ Jl. Adhiyaksa No. 2 Kayu Tangi, Banjarmasin \\ Email:yudikbs28@gmail.com,sobar.uniska@gmail.com,rahimsidiqs7q@gmail.com
}

\begin{abstract}
ABSTRAK
Air merupakan unsur terpenting bagi kelangsungan hidup di muka bumi. Sebab tanpa air kehidupan di muka bumi ini tidak akan ada. Semua mahluk hidup selalu memerlukan air untuk bisa tumbuh dan berkembang secara wajar. Seiring meningkatnya penduduk kota Amuntai yang mengakibatkan kebutuhan air bersih meningkat pula, sementara sarana air bersih dari PDAM masih terbatas. Berdasarkan alasan-alasan di atas, maka diperlukan suatu analisis perancangan pompa guna pemenuhan pemakaian air bersih yang dapat digunakan untuk menilai kelayakan suatu sistem distribusi untuk penyaluran air bersih. Pompa air yang sesuai untuk masalah ini ialah dengan menggunakan pompa sentrifugal. Pompa sentrifugal ialah jenis pompa dimana headnya dibentuk oleh gaya sentrifugal maupun lift yang ditimbulkan oleh sudu-sudu yang berputar. Dalam penelitian ini, difokuskan pada penelitian tentang pompa sentrifugal yang sesuai kapasitas air yang dibutuhkan untuk sebuah pompa dimana berdasarkan hasil perhitungan untuk setiap kapasitas air yg dipompa yaitu sebesar $422 \mathrm{~m}^{3} / \mathrm{jam}$ dan bentuk impeller yaitu : diameter dalam $(\mathrm{d} 1=0,214 \mathrm{~m})$, diameter luar $\left(\mathrm{d}_{2}=0,362 \mathrm{~m}\right),\left(\beta 1=17^{\circ}\right),\left(\alpha 1=62^{\circ}\right),\left(\beta 2=25^{\circ}\right),\left(\alpha 2=20^{\circ}\right),(\rho=172,7$ $\mathrm{mm}),(\mathrm{z}=11)$ dengan spesifikasi pompa yang digunakan sebagai masukan yaitu kecepatan motor penggerak $=1500(\mathrm{rpm})$, tebal sudu impeller $=5(\mathrm{~mm})$ dan tegangan torsi aman bahan shaft $(\mathrm{S} 45 \mathrm{C})=58\left(\mathrm{Kg} / \mathrm{mm}^{3}\right)$. Dari hasil perhitungan dapat disimpulkan bahwa kebutuhan air bersih yang semakin meningkat maka akan dibutuhkan pompa dengan spesifikasi yang lebih tepat pula dan dimensi impeller akan berubah sesuai dengan spesifikasi pompa yang dirancang sehingga kerja pompa lebih optimal untuk memenuhi kebutuhan air bersih pada tahun 2022.
\end{abstract}

Kata Kunci : Air bersih, Performa Mesin, Pompa Sentrifugal

\section{PENDAHULUAN}

Air merupakan unsur terpenting bagi kelangsungan hidup di muka bumi, sebab tanpa air kehidupan di muka bumi ini tidak akan ada. Semua mahluk hidup selalu memerlukan air untuk bisa tumbuh dan berkembang secara wajar.

Pertumbuhan jumlah penduduk yang meningkat berbanding lurus dengan meningkatnya kebutuhan akan air bersih. Selain pertambahan penduduk, ada beberapa faktor lain yang ikut mempengaruhi peningkatan kebutuhan air bersih yang berkaitan dengan aktivitas dan tingkat hidup manusia sendiri. Untuk itu diperlukan pelayanan air bersih yang baik kepada masyarakat, termasuk sistem jaringan distribusi air yang didukung oleh sesuainya kapasitas dorongan pompa, dan banyaknya pelanggan yang dilayani (Yuliana Rivai,dkk, 2006).

Hingga saat ini kuuantitas pelayanan PDAM khususnya di PDAM kota amuntai masih bisa dapat dan cukup konstan karena penduduk masih 
banyak yang menggunakan air tanah untuk memenuhi kebutuhan sehari-hari. Namun, hingga 2022 kebutuhan air bersih akan meningkat karena diiringi jumlah penduduk, yang meningkat pula,disamping itu jumlah air tanah yang berkurang akibat kebutuhan sehari-hari.

Dengan demikian berkembangnya wilayah perkotaan kota amuntai, maka sudah waktunya untuk mempertimbangkan kuantitas dan tekanan air agar tetap proporsional dan merata untuk di setiap jaringan pipa. Untuk itu diperlukan studi evaluasi jaringan perpipaan untuk mengetahui tingkat keproporsionalan dan pemerataan kualitas dan tekanan air yang ada diperpipaan. Hal ini dilakukan untuk menghindarkan tidak meratanya tekanan kuantitas air yang diterima oleh para pelanggan, yang nantinya dari studi ini akan direkomendasikan sistem jaringan perpipaan hasil evaluasi.

Berdasarkan alasan-alasan di atas, maka diperlukan suatu analisis perancangan pompa guna pemenuhan pemakaian air bersih yang dapat digunakan untuk menilai kelayakan suatu sistem distribusi untuk penyaluran air bersih. Studi ini hanya dibatasi pada peninjauan secara teknis.

\section{METODE PENELITIAN}

Metode yang kami lakukan dalam penelitian ini adalah :

\section{1) Penentuan Lokasi Penelitian}

Lokasi penelitian dilakukan langsung di Kota Amuntai dan di PDAM Kota Amuntai, yaitu dengan cara bertanya langsung dengan karyawan kemudian mengambil data-data yang diperlukan.Selain itu, data-data pelengkap diambil dikantor statistik untuk menunjang penulisan skripsi ini.

2) Pengumpulan data
Pengumpulan data ini berupa data-data berdasarkan dari jumlah penduduk, fasilitas-fasilitas di Kota Amuntai dan rencana tata ruang di Kota Amuntai sampai tahun 2022 yaitu :

Pengumpulan Data Sekunder

- Kondisi topografi, kependudukan, fasilitas kota.

- Rencana Tata Ruang Wilayah (RTRW) 2009-2022.

- Kondisi pemenuhan air bersih, kapasitas produksi, kapasitas distribusi, sumber air baku, intake, unit produksi, sisitem distribusi.

Pengumpulan Data Primer

- Pengumpulan data ini berupa tingkat permintaan (demand) masyarakat, kepuasan masyarakat yang sangat menentukan dalam tahapan peningkatan cakupan pelayanan.

- Wawancara dengan PDAM yang dilakukan dengan memberikan pertanyaan-pertanyaan yang menyangkut kebutuhan data yang akan digunakan untuk analisis untuk penentuan kebutuhan air bersih

\section{HASIL DAN PEMBAHASAN}

Perkiraan Jumlah Penduduk Pada Tahun 2022-2023 Yang Akan Datang

Kebijaksanaan kependudukan merupakan faktor yang penting dalam proses perencanaan rencana rata ruang wilayah, karena semua kebijaksanaan yang lain harus bermuara pada peningkatan kesejahteraan penduduk Kota Amuntai.

Tabel 4.1 Rencana distribusi penduduk kota Amuntai dapat dilihat pada tabel berikut :

\begin{tabular}{c|c|c|c}
\hline No & Tahapan & Tahun & $\begin{array}{c}\text { Jumlah Penduduk } \\
\text { (Jiwa) }\end{array}$ \\
\hline 1 & Tahap I & $2017-2018$ & 222.755 \\
\hline
\end{tabular}


p-ISSN 2502-4922,e-ISSN 2615-0867

\begin{tabular}{r|r|r|l}
\hline 2 & Tahap II & $2022-2023$ & 226.092 \\
\hline
\end{tabular}

Sumber : RTRW Kota Amuntai 20222023

Rencana kependudukan kota Amuntai tahun 2022-2023 disusun berdasarkan konsep rencana yang telah dibuat. Rencana kependudukan tahun 20222023 ditentukan berdasarkan beberapa aspek, diantaranya adalah sebagai berikut :

a) Intensitas kegiatan kota dan struktur penggunaan lahan pada masing-masing bagian wilayah kota.

b) Aksesibilitas antara kawasan dengan pusat-pusat pelayanan.

c) Kepadatan penduduk yang ada saat ini.

\section{Perkiraan Jumlah Pelanggan Pada Tahun 2022 Yang Akan Datang}

Dalam membuat perkiraan jumlah pelanggan sampai tahun 2022 dengan menggunakan tiga metode yaitu metode Aritmetika, metode Last-square, dan metode Geometri. Hal tersebut dilakukan untuk membandingkan metode mana yang menghasilkan perkiraan jumlah pelanggan yang paling besar dan selanjutnya akan digunakan sebagai dasar memperkirakan kebutuhan air bersih penduduk pada masa yang akan datang.

Dalam memperkirakan jumlah pelanggan, digunakan data-data jumlah pelanggan sebelumnya. Adapun datadata jumlah pelanggan PDAM Kota Amuntai yang menjadi data proyeksi adalah dari tahun 2012-2016. Hal ini dapat dilihat pada tabel berikut:

Tabel 4.2 Jumlah pelanggan PDAM Kota Amuntai

\begin{tabular}{c|c|c}
\hline No & Tahun & Jumlah Pelanggan \\
\hline 1 & 2012 & 14.001 \\
\hline 2 & 2013 & 14.663 \\
\hline
\end{tabular}

\begin{tabular}{c|c|c}
\hline 3 & 2014 & 15.781 \\
\hline 4 & 2015 & 16.366 \\
\hline 5 & 2016 & 17.086 \\
\hline
\end{tabular}

Data Teknis PDAM Kota Amuntai

Metode yang digunakan dalam memperkirakan jumlah pelanggan adalah sebagai berikut:

A. Metode Aritmetika

$$
\begin{aligned}
I & =\frac{p_{o}-p_{t}}{\mathrm{t}} \\
& =\frac{17086-14001}{5} \\
& =617
\end{aligned}
$$

Sehingga Persamaan menjadi :

$P_{n}=14.001+617 n$

Dimana :

Untuk tahun 2012, $\mathrm{n}=1$

Untuk tahun 2013, $\mathrm{n}=2$

Untuk tahun 2022, $\mathrm{n}=15$, maka diperoleh :

$$
\begin{aligned}
& \mathrm{P} 15=14.001+617(15) \\
& \mathrm{P} 15=23.256 \text { jiwa }
\end{aligned}
$$

B. Metode Last Square

Dari data jumlah pelanggan tahun 2012 - 2016, maka tahun dikaji dari $\mathrm{X}$ dan jumlah pelanggan dikajikan data $Y$.

Table 4.3 Penentuan data regresi

\begin{tabular}{c|c|c|r|r|r|r}
\hline No & Tahun & \multicolumn{1}{|c|}{$\mathrm{X}$} & $\mathrm{Y}$ & $\mathrm{X}^{2}$ & $\mathrm{Y}^{2}$ & $\mathrm{XY}$ \\
\hline 1 & 2012 & -4 & 14.001 & 16 & 196.028 .001 & -56.004 \\
\hline 2 & 2013 & -3 & 14.663 & 9 & 215.003 .569 & -43.989 \\
\hline 3 & 2014 & -2 & 15.781 & 4 & 249.039 .961 & -31.562 \\
\hline 4 & 2015 & -1 & 16.366 & 1 & 267.845 .956 & -16.366 \\
\hline 5 & 2016 & 0 & 17.086 & 0 & 291.931 .396 & 0 \\
\hline & $\sum$ & -10 & 77.897 & 30 & 1.219 .848 .883 & -147.921 \\
\hline
\end{tabular}

$$
\begin{aligned}
a & =\frac{(N)\left(\sum x y\right)-\left(\sum x\right)\left(\sum Y\right)}{(\mathrm{N})\left(\sum X^{2}\right)-\left(\sum X\right)^{2}} \\
= & \frac{(5)(-147921)-(-10)(77897)}{(5)(30)-(100)} \\
& =787,3 \mathrm{jiwa}
\end{aligned}
$$


p-ISSN 2502-4922,e-ISSN 2615-0867

$$
\begin{aligned}
b & =\frac{\left(\sum x^{2}\right)\left(\sum y\right)-\left(\sum x\right)\left(\sum x Y\right)}{(\mathrm{N})\left(\sum X^{2}\right)-\left(\sum X\right)^{2}} \\
= & \frac{(30)(77897)-(-10)(-147921)}{(5)(30)-(100)} \\
& =17154 \text { jiwa }
\end{aligned}
$$

sehingga diperoleh :

$\mathrm{Y}=787,3 \mathrm{X}+17.154$

$X=(2008-2022)=15$, dimana $X$

adalah tahun proyeksi.

Maka diperoleh :

$\mathrm{Y}_{15}=787,3(15)+17.154$

$\mathrm{Y}_{15}=28.963,5$ jiwa $\approx 28.964$ jiwa

C. Metode Geometri

Dari data jumlah pelanggan PDAM Kota Amuntai kita dapat menentukan besarnya rasio pertambahan jumlah pelanggan dengan menggunakan rumus :

$$
\begin{aligned}
r & =\left(\frac{P_{o}}{P_{t}}\right)^{1 / t}-1 \\
& =\left(\frac{14001}{1,0406}\right)^{1 / 5}-1 \\
& =0,0406
\end{aligned}
$$

Sehingga jumlah pelanggan sampai tahun 2022 dapat dihitung dengan menggunakan persamaan :

$$
\begin{aligned}
& P_{n}=P_{0}(1+r)^{n} \\
& P_{15}=17.086(1+0,0406) \\
& P_{15}=31.038 \text { jiwa }
\end{aligned}
$$

Dari hasil perhitungan di atas, bahwa perkiraan jumlah pelanggan PDAM Kota Amuntai terbesar diperlihatkan pada metode Last-Square. Adapun hasil perhitungan selengkapnya dapat dilihat pada tabel 4.3 berikut :

Tabel 4.4 Perkiraan jumlah pelanggan PDAM Kota Amuntai 2016-2022

\begin{tabular}{c|c|c|c}
\hline \multirow{2}{*}{ Tahun } & \multicolumn{3}{|c}{ Metode } \\
\cline { 2 - 4 } & Aritmetika & Last-square & Geometri \\
\hline 2016 & 19.554 & 24.240 & 24.445 \\
\hline 2017 & 20.171 & 25.027 & 25.438 \\
& & & \\
\hline
\end{tabular}

\begin{tabular}{c|c|c|c}
\hline 2018 & 20.788 & 25.814 & 26.471 \\
\hline 2019 & 21.405 & 26.602 & 27.545 \\
& & & \\
\hline 2020 & 22.022 & 27.389 & 28.664 \\
\hline 2021 & 22.639 & 28.176 & 29.827 \\
\hline 2022 & 23.256 & 28.964 & 31.038 \\
\hline
\end{tabular}

\section{KESIMPULAN}

Dari hasil analisis perancangan pompa guna pemenuhan kebutuhan air bersih PDAM Kota Amuntai, maka dapat ditarik kesimpulan sebagai berikut

1. Kapasitas air yang dibutuhkan masyarakat Kota Amuntai sampai tahun 2022 yaitu 234,541/s, sedangkan kapasitas produksi saat ini 1501/s, sehingga kapasitas tambahan sebesar 84,541/s.

2. Berdasarkan hasil perhitungan Head Total Pompa diperoleh hasil $82 \mathrm{~m}$.

3. Berdasarkan hasil perhitungan untuk setiap kapasitas air yang dipompa yaitu sebesar $422 \mathrm{~m}^{3} / \mathrm{jam}$ atau $0,117 \mathrm{~m}^{3} / \mathrm{s}$

4. Spesifikasi pompa yang digunakan sebagai masukan yaitu :

- Jenis pompa = pompa sentrifugal

- Kecepatan motor penggerak, $\mathrm{n}$ $=1500(\mathrm{rpm})$

- Tebal sudu impeller, $\mathrm{s}=5$ (mm)

- Tegangan torsi aman bahan shaft, pipa hisap dan pipa tekan yaitu $(\mathrm{S} 45 \mathrm{C}), \tau=58\left(\mathrm{Kg} / \mathrm{mm}^{2}\right)$

\section{REFERENSI}

[1] Data Teknis PDAM Kota Amuntai

[2] Dietzel | F. 1998. Turbin, Pompa dan Kompresor. Erlangga, Jakarta.

[3] Haruno Tahara, Sularso. 2000. Pompa dan Kompresor. Pradnya Paramita, Jakarta. 
[4] Husaini Usman, M.Pd. dan R.Purnomo Setiady Akbar, S.Pd., M.Pd. 2003, Pengantar Statistik, PT Bumi Aksara, Jakarta.

[5] Maindoka, Hendra Panjaitan. 2011. Analisis Pemakaian Air Bersih (PDAM) Untuk Kota Pangkep 10 Tahun Ke Depan, Universitas Hasanuddin Makasar

[6] Nieman, G. 1999. Elemen Mesin Jilid 1 Desain Kalkulasi Dari Sambungan, Bantalan dan Poros. Jakarta: Erlangga.

[7] Stoecker, W. F dkk. 1996, Refrigerensi dan Pengkondisian Udara. Erlangga, Jakarta.

[8] Suhono, Andreas, dkk. 2007. Buku Panduan Pengembangan Air Minum RPIJM. Departemen Pekerjaan Umum.

[9] Yuliana Rivai, Ali Masduki, Bowo Djoko Marsono. 2006. Evaluasi Sistem Distribusi dan Rencana Peningkatan Pelayanan Air Bersih Pdam Kota Gorontalo, Jurnal SMARTek. 